\title{
Student-Led Seminars as a teaching-learning method- effectiveness of a modified format
}

\author{
Kadayam Guruswami Gomathi ${ }^{1}$, Ishtiyaq Ahmed Shaafie ${ }^{1}$ and Manda Venkatramana ${ }^{1}$
}

\begin{abstract}
Background and objectives: Student-led seminars (SLS) are being used as a teaching-learning method for undergraduate medical students in the Gulf Medical University, Ajman. Student feedback, however, ranked SLS as a poor teaching-learning method. Objectives were to assess effectiveness of a modified format for student-led seminars in the undergraduate medical curriculum.
\end{abstract}

Methods: SLS was modified into a presentation followed by a quiz, to make it more interactive and student centred. The new format was implemented midway in the academic year. Student perceptions regarding SLS sessions were surveyed using an anonymous questionnaire and scored using a likertlike scale. Statistical significance $(\mathrm{p}<0.05)$ was tested using the Wilcoxon signed ranked test using the SPSS19 software.

Results: The new format was reported to be significantly more interesting, interactive, fun and made them feel more like a team. High number of students reported "gained new knowledge", "enjoyed learning through seminars", "learnt new things from my colleagues in the seminar group" and "enjoyed working with my colleagues for my seminar". Scores for "improvement in communication skills", "learnt to make a formal scientific presentation" and "gained self-confidence after presenting the seminar" were also high.

Conclusions: Since the main use of SLS as a teaching-learning method in Gulf Medical University, Ajman is to inculcate self-learning, peer-learning, teamwork and communication skills, the new format is significantly better at achieving the outcomes.

Key words: Student-led seminars, undergraduate medical education, teaching-learning method

\section{Introduction}

Student-led seminars (SLS) are used as a teaching-learning strategy in the medical curriculum of the Gulf Medical University. Students are expected to develop competencies in information retrieval, identify reliable sources, organize the information and communicate it effectively to peers using available information technology tools. Since students work in groups, they are also expected to develop teamwork skills.

${ }^{1}$ Gulf Medical University, Ajman, UAE

Corresponding author:

Dr. KG Gomathi, Associate Professor,

Department of Biochemistry, Gulf Medical University, Ajman, UAE.

E-mail: gomathikg@gmu.ac.ae,gomathikg@hotmail.com.
Topics for SLS integrate across disciplines, have social and awareness components besides knowledge are not learnt in any other way during the course, have specific learning objectives and offer opportunities to explore beyond the textbooks and the medical disciplines. Examples of SLS topics in the first year are 'Food safety', 'Eating disorders' and 'Health impact of disasters'. Knowledge, communication and teamwork skills are assessed during the SLS. Associated knowledge is also assessed in summative examinations. Though SLS is considered an important teaching-learning strategy, it had consistently received poor ratings in studentfeedback over the past 3 years. Focus group discussions with students highlighted areas of concern. Students presenting the SLS viewed it as "an activity aimed at satisfying the assessing faculty". Students attending the SLS did not find it "any different from a lecture" nor 
"interesting/interactive" and "there was no incentive to participate actively" during the sessions. There was need, therefore, to modify the SLS to make it student-centred, interactive and to assess the effectiveness of the new format.

\section{Methods}

For SLS, students are divided into groups of 4 and allotted topics by drawing lots. They work together as a team, prepare and present the seminar to peers on specified dates. The new format of the SLS was introduced midway in the first year of the curriculum (2011-2012) after five SLS sessions had been conducted in the old format. In the new SLS, the same student groups and topics were retained. However during the SLS, students were seated as teams in the classroom. At the end of the presentation an oral quiz was conducted on the topic by the faculty facilitator. Student teams were allotted questions by drawing lots. Each question was projected on the screen and the team given 60 seconds to answer the question. If the team got the answer right they were awarded marks. If not, the question passed to the next team who got a chance to score bonus marks. Marks scored were added to the summative assessment. Rubric used to assess knowledge, communication and teamwork skills of the presenting students remained unchanged.

Students' $(n=60)$ perceptions were surveyed at the end of the year using a self-administered, anonymous questionnaire designed by faculty members, validated and pilot tested on three students. First part included items on general perceptions regarding SLS and the second part had comparisons between the two formats. Students responded to closed-ended questions on a likert-like scale from 1 to 5 . Data was analyzed using SPSS 19 software (IBM, Chicago, USA). Results are expressed as mean likert scores.

\section{Results}

Significantly higher number of students reported "feeling like a team member" (Figure 1).

Figure 1: Comparison of the perceptions regarding SLS in the old and new formats

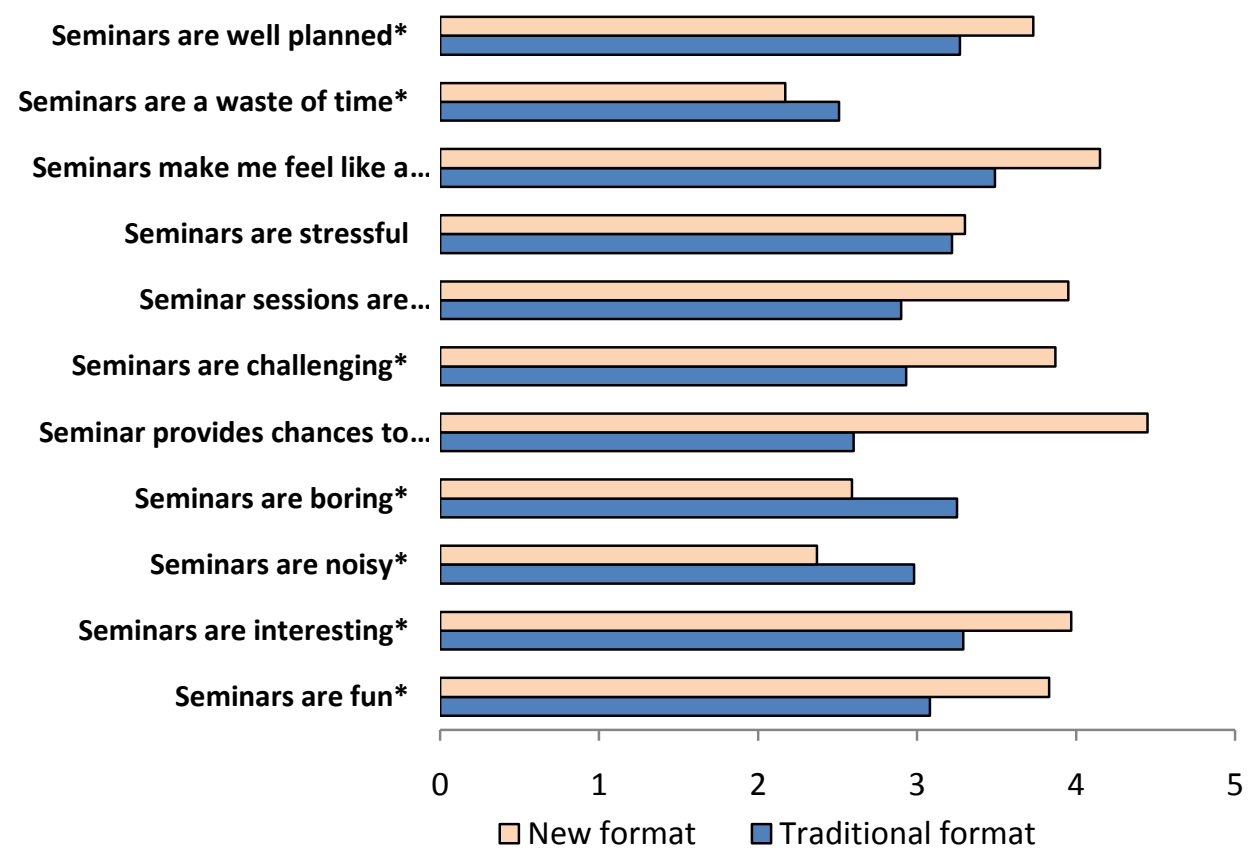

Values shown are mean scores on the likert-like scale.

*Significant difference $(p \leq 0.05)$ between the median scores of the two formats tested using the Wilcoxon signed rank test.

The new format was more "challenging" but not "stressful". Seminars in the new format were significantly more "interesting", "fun" and "interactive". Fewer students found it "boring" or a "waste of time". Students felt the new format gave them "opportunity to score marks". General perceptions regarding seminars were good. "Gained new knowledge 
in seminars (4.10)", "learnt new things from my colleagues (4.06)", "enjoyed working with my colleagues (4.06)", "presenting the seminar improved my communication skills (4.11)", "I now know how to make a formal scientific presentation (4.14)" and "I have gained selfconfidence after presenting my seminar (4.03)" received high scores.

\section{Discussion}

Changed seating arrangements and participation as teams in quizzes appears to have increased their sense of belonging to a team since more students reported feeling like a team member in the new format. Significant differences in performance related to seating arrangements in the classroom have been also reported by Zomorodian, et al., (2012). The new SLS was perceived as more interesting, interactive and as an opportunity to score marks suggesting an increase in active learning. Group composition, active student participation, interaction and assessments have all been reported as factors that influence seminar learning by Spruijt et al., (2012).

We could not get general perceptions regarding SLS for this batch of students before the format was changed. However general perceptions surveyed after implementation of the new SLS were significantly better than that observed with previous batches of students in the old format (data not shown). Significantly more students felt that they had gained new knowledge in the seminars (4.1 vs. 3.12), learnt from colleagues (4.06 vs. 3.24), enjoyed working with colleagues (4.06 vs. 3.22), improved communication skills (4.11 vs. 3.76 ) and learnt to make formal scientific presentations (4.14 vs. 3.71). Dandavino, et al., (2007) suggest that medical students become more effective communicators and better learners as a result of peer teaching. Student perceptions regarding peer learning show the new SLS to be very effective. Gain in knowledge perceived is probably because the learning is active and reinforced by the quiz at the end of the SLS.

Teamwork is being increasingly emphasized in healthcare and team training is now considered essential in medical education (Lerner et al., 2009). Though this study is limited to first-year medical students, results show more students in the new format enjoyed working together and learnt from each other which are very encouraging.

\section{Conclusions}

The new format of the SLS seems to be significantly better in encouraging students in self, active and peer-learning. Teamwork and communication skills are also learnt effectively in the new format.

\section{Limitations}

All conclusions are based on student perceptions. Effectiveness of the new SLS format on gain in knowledge as evidenced by scores in examinations is being studied.

\section{Recommendations}

The main rationale in using SLS as a teachinglearning method is to develop generic and transferable skills of life-long learning and communication. The new SLS format can be tried out in other programs as well since outcomes addressed are generic in nature.

Conflict of interest: There was no conflict of interest for any of the authors. Participation by students was voluntary and anonymous and no ethical issues were identified.

Acknowledgments: We thank the second and third year medical students for participating in the focus group discussions and the first year students for participation in the surveys.

\section{References}

Dandavino, M., Snell, L. \& Wiseman, J. (2007) Why medical students should learn how to teach, Medical Teacher, 29, 6, pp. 558-565.

Lerner, S., Magrane, D. \& Friedman, E. (2009) Teaching Teamwork in Medical Education. Mount Sinai Journal of Medicine: A Journal of Translational and Personalized Medicine, 76(, 4, pp. 318-329.

Spruijt, A., Jaarsma, A.D.C., Wolfhagen, H.A.P., van Beukelen, P. \& Scherpbier, A.J.J.A. (2012) Students' perceptions of aspects affecting seminar learning, Medical Teacher, 34, 2, pp.e129-e135.

Zomorodian, K., Parva, M., Ahrari, I., Tavana, S., Hemyari, C., Pakshir, K., et al. (2012), The effect of seating preferences of the medical students on educational achievement, Medical Education Online, $17 . \quad$ doi: 10.3402/meo.v17i0.10448. Epub 2012 May 16. 